\title{
Chapter 5 \\ Laboratory Work in Education of Food Technology Professionals
}

\author{
Maksudakhon Abdullaeva
}

\subsection{Introduction}

A laboratory class allows integrating theoretical and methodological knowledge, practical skills of students into a single teaching and research process. Increasing their role is associated with the rapid development of the experiment in its modern form, as a result of which virtually all university graduates should be prepared for research work.

The meaning of the word "laboratory" speaks for itself as it stands for the old notion of mental and physical effort to solve scientific or life-related tasks. The word "practicum" has the same meaning - the Greek word "practices" means "practical, active" standing for training exercises requiring intensive activities. Many fields of study have their specifics in laboratory exercises.

Joint work in groups is a very efficient way of conducting laboratory activities. Supervision of these exercises requires many efforts by instructors; they have to organize practical classes to facilitate students' in-depth independent work, engage students' mental activities, and provide them with methodology of performing practical exercises.

Exercises are crucial for practical classes. Exercise is an example discussed from the theoretical point of view. Usually attention is paid to the development of specific skills and abilities; thus, it determines students' basic activities, such as addressing issues, creating graphic projects, and clarifying categories and scientific concepts all being prerequisites for creative thinking and strong speaking skills.

\footnotetext{
${ }^{1}$ From the Latin word "labora" - work, labor.

M. Abdullaeva $(\bowtie)$

Department Technology of Food Production and Standardization, Technological University of Tajikistan, Dushanbe, Tajikistan e-mail: Max-250757@mail.ru
} 
Laboratory work is crucial in many fundamental, engineering, and special fields of study that are taught at universities. Those represent one form of learning activity and practical teaching methods where students create and perform experiments and tests by using special equipment, devices, testers, and other technical means. For example, in microbiology laboratory class, students comprehend, observe, and study microorganisms, bacteria, and fungus and study composition, operation, and measurement methods.

Laboratory work is necessary for achieving educational, didactic, and developmental goals within fields of study and their components (Ploskonosova 2002).

As a result, they provide interaction between theory and practice; encourage independence and ability to set and perform own experiments; facilitate comprehension, analysis, and design; strengthen ability to evaluate outcomes; and ensure the practical application of knowledge. For fields of study, laboratory work ensures introduction to equipment, devices, testers, and research techniques. In other words, students complement theory with factual data and, thus, identify and verify theoretical correlation (Skatkin 1980).

Microbiological production occupies one of the leading places in modern biotechnology and belongs to industries whose production volume is constantly growing, and the scope of application is steadily expanding. The successful development of the microbiological industry largely depends not only on deep knowledge in the field of production but also on the ability to solve emerging problems in the creation of new technologies of knowledge in the field of microbiology, biochemistry, genetics, and ecology of microorganisms. This determines the purpose of this course the formation of students' basic ideas about the functioning of microbial populations and the possibility of managing them under industrial production conditions. (Ploskonosova 2002).

It defines the purpose of the course - formation of students' basic understanding of the microbial population's development and their management capabilities in terms of industrial production.

When learning microbiology, students should know:

- Basics of morphology and physiology of prokaryote (bacteria) and eukaryote (filamentous fungi and yeast)

- Cultivation and growth of microorganisms and environmental effects on microorganisms to handle their activity

- Food production microorganisms and spoilage microorganisms

- Basics of microbiological control at food production

Student has to:

- Learn microscopic examination and drug preparation methods

- Study microorganism sterilization and cultivation techniques

- Get acquainted with the methods of sterilization and cultivation of microorganisms

- Have an idea of the role of microorganisms in the formation of quality and safety of raw materials and finished products of the plant origin 
An important place in the study of microbiology is the conduct of laboratory work. Essence of laboratory works consists in the use of practical training methods for the formation of new knowledge and practical skills (Ploskonosova 2002).

Depending on laboratory tasks, laboratory work falls into introductory, experimental, and problem-solving types.

At introductory laboratory classes, students study design and composition of production means (equipment, devices, tools, etc.), research means (testing units and gauges, etc.), and learn calibration and alignment techniques.

Experimental laboratory work follows experimental and research goals. Students might be tasked to study and master different research methods (e.g., methods to measure impact hardness at researching structural resistance); to construct, reconstruct, and completely construct various schemes (e.g., constructing electrical circuits to measure properties, changing design of gear mechanism to achieve variation of gear ratio); to study effects of various factors on object properties; to determine degree of conformity of experimental and calculation data; to verify, demonstrate, and confirm rules and consistent patterns; etc.

Problem-solving exercises also include organization and implementation of experiments. The difference is only in the level of the problem studied. The level of the problem means the level of complication for students: new object and new experiment conditions. Exercises to verify various hypotheses of educational and the scientific level of the problem fall under this group of laboratory practices.

Based on the activity-based approach to analysis of laboratory work, its structure includes the following stages:

- Introduction and motivation

- Operation and learning

- Control and evaluation

- Completion

The introduction and motivation stage involves definition and communication of laboratory theme, formulation of didactic and developmental goals, and motivation to achieve a goal. Operation and learning is the core of the whole process. It assumes preparation to practical exercises and actual performance. In the preparation phase, the instructor identifies methodology of using available knowledge, recommended sequence of activities, and organization of the work. At this stage, students receive a list of tasks and exercises, methodology of using available knowledge, and recommended sequence of activities. The instructors organize the process of the didactic project and actual implementation of laboratory work.

At the control and evaluation stage, students process experimental data and outcomes of laboratory tasks, summarize and give conclusions, and assess if they have achieved the goal (Poliakova 2015, pp. 188-190).

The completion stage means writing a report and submitting it to the instructor. Every stage is unique in its design, organization, and implementation. Details are provided below. 


\subsection{Introduction and Motivation Stage}

\subsubsection{Choosing and Defining the Topic}

The topic of laboratory work is part of the curriculum; it is described in detail in a training program depending on students' major, number of hours allocated for laboratory classes, and availability of laboratory resources. Laboratory works that are more important for vocational training and strengthening practical aspects of future work go first in curriculum.

The definition of a laboratory work topic shall include necessary components of the primary objective to be addressed during class and indicate students' actions toward the objective. Action verbs to describe students' activities are - to study, to design/construct, to define, etc. Components of the primary objective are:

- Object - part of a tangible world, process, and phenomenon addressed at laboratory work

- Subject - part of object for study or research

- Procedure - nature, kind, and method of impacting an object to achieve result

- Object, subject, and procedure shall be new to students (Skatkin 1980).

\subsection{Forms of Students' Arrangement in Laboratory Work}

Organization of laboratory activities may differ depending on a method of conduct: frontal, cyclic, or individual. The characteristic of preparation and conduct determines the difference in organizing laboratory work: individual or group based. In the latter, case instructors need to think over rationale for group arrangements (chain, net, star, and methodology of group roles - identifying a leader) (Skatkin 1980).

- With the frontal form of the organization of classes, all students perform the same work simultaneously.

- In the group form of the class's arrangement, the same work is conducted in small groups of 2-5 people.

- At the individual form of organization of classes, each student performs an individual task (Skatkin 1980).

\subsection{Definition of a Laboratory Work Goal}

Goal - expected result, indication of a future state of a system (object). Since laboratory classes present one type of training, the goal of this activity is to modify student's personality. In the cognitive part of student's personality, these 
modifications may be characterized as standards of learning activity with indication of maturity level in compliance with goal taxonomy:

- Carry out actions based on external source of information (schemes, algorithms, instructions, etc.).

- Carry out actions independently on the grounds of available knowledge and methodology.

- Carry out automatic actions, i.e., properly shaped skills and abilities.

Often the objectives of laboratory work are formulated by the professors through the actions of the teacher (to form, develop, provide.) Or through the purpose of the experiment (determine the magnetic permeability, measure the hardness of steel). However, such formulations do not provide an opportunity to assess whether the main goal is achieved - a change in the personality of the learner, whether his/her ability to perform certain practical actions is formed.

The goal setting should provide an opportunity to diagnose the achievement of the objectives of the lesson. For example, the purpose of laboratory work is to study methods for measuring the hardness of metallic materials and to build the ability of students to measure the hardness of such materials. Proof of achievement of this goal will be the ability to independently and correctly choose the method of measuring hardness, perform such measurements, and evaluate the accuracy of the hardness determined (Dogadin 2003, p. 199).

Motivation for laboratory work often develops through describing practical and professional significance of outcomes, ensuring interest to the topic, encouraging competitiveness, etc. For instance, if you learn the method of measuring metal hardness you can apply it to control the heating of food item.

\subsection{Operation and Learning Stage}

\subsubsection{Developing a List of Learning Tasks for Laboratory Class}

Practical tasks solved during classes and performed in specific conditions by specific methods are means to achieve the didactic goal of laboratory work. These phases of achieving the goal develop on the ground of a general task breakdown and determine the action plan on solving the given task.

Components of the task structure: subject (task in its initial state), product (model of a required (end) state of a subject), requirements to task, procedure leading to modification of a task subject, means, approaches, and methods to achieve the final (end) state of a subject. If the procedure is explained to students, their activities will be just to reproduce; however, if the procedure is unknown or presented in general words, students become more creative. A list of laboratory work tasks, presented this way, allows making a plan of implementing operation and learning stage. 
Important to note, that the plan can be fulfilled if only necessary material resources are available. Otherwise, there is a need to modify the plan to take into account the availability of material resources.

\subsubsection{Application of Reference Knowledge and Work Methods}

Basic theory application is necessary to implement practical objectives of a laboratory work.

Students may learn this part during classes or in preparation to the classes. Before granting access to the practical part of the work, instructors need to examine the knowledge of reference material with special focus on safety rules. In introductory laboratory work, description of reference material is usually part of input data: fullscale specimen, schemes, equipment, devices, etc.

Planning a laboratory class requires consideration of its type (introductory or experimental), as well as developing its plan requires selection of its type traditional or factorial. Traditional plan assumes changes only in one independent variable and in factorial variables may be two or more.

Formation of an indicative basis (recommended sequence) of activities. Any action, including students' laboratory work, involves orientation, implementation, control, and correction. Orientation of activities is directed at correct and reasonable/ rational set of the implementation part or selection of an implementation format. Its content may vary and differ in completeness of the stipulation activity conditions as well as in generality and production method. Completeness of a recommended sequence of activities may have or may lack structural components like:

- Object to be transformed or baseline for activity (problems, tasks, preparations, materials, scheme components, etc.)

- End product or result expectations (constant pattern description, numerical result, model, scheme, sample, product, etc.)

- Resources for activities (handbooks, tables, devices, tools, knowledge of procedures and rules, transformation methods, methods of procedure: mental and physical)

- Process technology (algorithm, design formula, demonstration or description of sequence of activities in kind of guidelines, flowchart, etc.) (Hutorskyi 2001)

Educational experiments are another special type of laboratory work. This type of experiments address two objectives: work to learn the methodology of measuring various features and work to study object behavior and properties, measurement of given properties depending on experiment conditions. In the latter, measurement methods serve as a framework, base operations used by students during research activities. 
As a result of experimental laboratory work, for learning measurement methods, students will have to demonstrate abilities to determine object properties, measure properties with given methods, and, at a required quality level, apply methods to reveal and measure object properties to carry out experiments. Students will also have to verify precision of measurements, interpretation of nature, etc. Without proper knowledge of research and measurement methods, students will not be able to perform laboratory tasks to study the relationships and effect of miscellaneous factors due to the fact that experiment results may turn out unreliable. To performing laboratory work in order to learn measurement methods, students need to practice evaluation of measurement precision, note systematic, and random margins of error of credible interval and feasibility of using some methods and equipment (Chernilovskyi 2002).

Experimental work of a second type requires an action plan and performance algorithm. Due to didactic character, algorithms may be:

\section{- Reproduction algorithm}

- Practical laboratory task is addressed in strict conformity with set of rules; students follow this set of rules in reproducing operations (formal sequence of actions).

- Algorithm of identification

- Verbal description is replaced with drawings and photos; students have to assemble a scheme or mechanism in compliance with the given drawings and photos. Students have to identify parts of a given device, know how to read drawing legends, and distinct scheme elements to create a mechanism or scheme.

- Problem-solving algorithm

- It is the system of general rules and operations; students perform research activities directed at solution of a problem situation acting in a certain sequence.

Implementation of practical exercises may differ depending on a type of a suggested algorithm. If in an introductory laboratory work they use algorithm of identification, in experimental work to study methodology, they use reproduction algorithm. In research laboratory work, together with reproduction algorithms, they apply a problem-solving algorithm (Dogadin 2003; Poliakova 2015, pp. 188-190).

\subsection{Control and Evaluation Stage}

The goal of this stage is to process, analyze, and evaluate results and to make conclusions.

The control and evaluation stage of laboratory work is the activity of monitoring and evaluating the course and results of a particular process.

Control is the process of comparing a controlled object, activities with standards, norms, and criteria. Evaluation is an oral or written expression of control results. 
In connection with the ideas to modernize education, control and evaluation must be changed radically. And then immediately the following questions are arising:

- What to evaluate?

- Who evaluates?

- How to evaluate?

And in no case should you confuse the two concepts - the "mark" and the "evaluation".

A mark is a quantitative measure of the level of knowledge and skills of a student. The marks of the student are fixed in the special documentation (in journal); the scale of marks rigidly establishes the level of mastering by the student of the uniform state program of the educational standard. In fact, the mark is formal.

Evaluation is a definition and expression in conventional marks, points, as well as in evaluative judgments of the teacher concerning the degree of mastering the knowledge and skills by the student established by the program, the level of diligence, and the state of the discipline. It can vary in any possible way.

Evaluation determines the nature of the students' personal efforts, establishes the depth and scope of individual knowledge, and promotes adjustment of the student's motivational and needs sphere. The assessment is emotional.

\subsection{Learning Outcomes (Mastered Skills, Acquired Knowledge)}

The main goal of the discipline teaching is in-depth study of the foundations of general and industrial microbiology and microbiology of food production. Formation of a scientific world outlook on the role of microorganisms in various processes of processing and storing food products. This will allow future bachelors to ensure a high level of sanitary-hygienic state of production, prevent losses, and get benign products, accounting for the main patterns of development of a technically useful and harmful microflora in the development of new types of food products.

Mastered skills:

- To provide aseptic conditions for working with biomaterials

- To use microscopic optical technology

- To conduct microbiological studies and evaluate the results obtained

- To observe the rules on personal hygiene and industrial sanitation and apply the necessary methods and means of protection

- To prepare solutions of disinfectants and detergents

- To disinfect equipment, inventory, premises, transport, etc.

- Master microscopy technique and the technique of preparing microbial agents and to get acquainted with methods of sterilization and cultivation of microorganisms 
- To have an idea of the role of microorganisms in the formation of quality and safety of raw materials and finished products of plant origin

Knowledge acquired:

- The main groups of microorganisms, their classification

- The importance of microorganisms in nature and human life

- Microscopic and cultural studies

- Rules for selection, delivery, and storage of biomaterial

- Methods of sterilization and disinfection

- Concepts of pathogenicity

- Sensitivity of microorganisms to antibiotics

- Forms of exposure of pathogenic microorganisms to the organism

- Microorganisms used in industry enterprises and microorganisms - pests of food production

- The basis of microbiological control at the industrial enterprises

At the end of a laboratory work, students have to write a performance report in compliance with requirements for content and result evaluation criteria.

Reports should include:

- Correct title of the laboratory work

- Goals and objectives

- Test record (if applicable) or testing process protocol

- Tables, diagrams, and revealed correlation

- Conclusions

- Evaluation of results (to what extent results correspond to goals) (Ploskonosova 2002)

\subsection{Conclusions}

Microbiology (from the Greek micros (small), bios (life), logos (science)) - the science of the smallest, invisible to the naked eye organisms. Microbiology studies morphology, physiology, genetics, systematics, and ecology of microorganisms and their relationships with other beings.

Nutritional microbiology is based on knowledge of general microbiology; organic, physical, and colloid chemistry; and biochemistry and serves as a theoretical basis for any food technology.

Laboratory classes on discipline "microbiology" - an important stage in the training of engineers-technologists of food production. For their implementation, the student must familiarize himself with laboratory equipment, as well as with the technique of conducting basic laboratory operations. 
Since microbiology laboratory contains electrical appliances, pure cultures of various microorganisms, students must strictly observe the rules of internal regulations and safety precautions. Before each laboratory work, the student should study the relevant section of the textbook, a summary of lectures, and a description of laboratory work.

When preparing a report on the work done in the workbook, it should be written down the date, the results obtained during the performance of laboratory work, and the conclusions. Conclusions should be consistent with the stated goal of the work.

In laboratory works, the use of methods of problem training is envisaged: business game, solution of situational tasks, search method, and elements of research work.

The application of the search method is realized when the students compile their conclusions after completing each task, as well as in a group discussion of the results obtained, when it is necessary to explain the results obtained.

Laboratory work on the discipline "microbiology" is a very important form of training, as they allow students to deepen and expand theoretical knowledge, to get acquainted with practical techniques for determining the raw materials quality and finished products, and to master the methods on experimental research and the results processing.

In laboratory classes in microbiology, students perceive, observe, investigate natural phenomena and technical and other processes, study the technology objects, and acquire skills in working with a microscope.

As a result of studying this course, students should distinguish the main groups of organisms, learn the characteristics of the metabolism of microorganisms, gain skills in working with a microscope, master the sampling skills for microbiological analysis, be able to perform microbiological analysis, understand the impact of environmental conditions on microorganisms and terms of food storage, and know the basics of hygiene and sanitation and existing rules and regulations.

\section{References}

Chernilovskyi, D. V. (2002). Didakticheskaia teoria v vyshei shkole. Moskva: Uniti-Dana. Available online at http://www.books.ru/books/didakticheskie-tekhnologii-v-vysshei-shkoleuchebnoe-posobie-dlya-vuzov-40720/\#. Checked on 17 Dec 2016.

Dogadin, N. G. (2003). Usilenie laboratornogo praktikuma v teoreticheskoi podgotovke studentov. In Fisika $f$ sistemie sovreme sovremennogo obrasovanija (FCCO-03): Trudui sedmoui Meschdunarodnoi konferenzii. Sankt-Peterburg.

Hutorskyi, A. V. (2001). Soveremennaia didaktika. Uchebnik dlia vuzov. Sankt-Peterburg: Piterbuk. Available online at https://www.ozon.ru/context/detail/id/27961706/. Checked on 17 Dec 2016.

Ploskonosova, L. I. (2002). Metodicheskie ukazania k laboratornym rabotam. Mikrobiologia hlebopekarnogo, makaronnogo i konditerskih izdelyi. Kemerova: KemTIPP. Available online at https://domashke.net/referati/ostalnye-referaty/uchebnoe-posobie-metodicheskie-ukazaniyak-laboratornym-rabotam-po-discipline-mikrobiologiya-moloka-i-molochnyh-produktov-dlyaspecialnosti-2710tehnologiya-moloka-i-molochnyh-produktov. Checked on 17 Dec 2016. 
Poliakova, T. A. (2015). Laboratornye raboty kak sredstvo motivacii i aktivizacii uchebnoi deiatelnosti uchashihsia. In Omskyi Nauchnyi Vestnik (4), Available online at http://elibrary.ru/item. asp?id=24254743. Checked on 17 Dec 2016.

Skatkin, M. N. (1980). Problemy sovremennoi didaktiki (1st ed.). Moskva: Prosveščenie. Available online at http://pedlib.ru/Books/3/0167/3_0167-1.shtml. Checked on 17 Dec 2016.

Open Access This chapter is licensed under the terms of the Creative Commons Attribution 4.0 International License (http://creativecommons.org/licenses/by/4.0/), which permits use, sharing, adaptation, distribution and reproduction in any medium or format, as long as you give appropriate credit to the original author(s) and the source, provide a link to the Creative Commons license and indicate if changes were made.

The images or other third party material in this chapter are included in the chapter's Creative Commons license, unless indicated otherwise in a credit line to the material. If material is not included in the book's Creative Commons license and your intended use is not permitted by statutory regulation or exceeds the permitted use, you will need to obtain permission directly from the copyright holder.

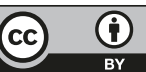

